\title{
Article
}

\section{Hollow Silica Particles: A Novel Strategy for Cost Reduction}

\author{
Daron Spence ${ }^{1,2}$, David A. Cullen ${ }^{3}$, Georgios Polizos ${ }^{1} \oplus$, Nitin Muralidharan ${ }^{1}$ and Jaswinder Sharma ${ }^{1,4, *}$ \\ 1 Electrification and Energy Infrastructure Division, Oak Ridge National Laboratory, Oak Ridge, TN 37830, \\ USA; dspence@gatech.edu (D.S.); polyzosg@ornl.gov (G.P.); muralidharan@ornl.gov (N.M.) \\ 2 School of Materials Science and Engineering, Georgia Institute of Technology, Atlanta, GA 30332, USA \\ 3 Center for Nanophase Materials Science, Oak Ridge National Laboratory, Oak Ridge, TN 37830, USA; \\ cullena@ornl.gov \\ 4 Building Technologies Research and Integration Center, Oak Ridge National Laboratory, \\ Oak Ridge, TN 37830, USA \\ * Correspondence: sharmajk@ornl.gov; Tel.: +1-865-241-2333
}

Citation: Spence, D.; Cullen, D.A.; Polizos, G.; Muralidharan, N.;

Sharma, J. Hollow Silica Particles: A Novel Strategy for Cost Reduction. Nanomaterials 2021, 11, 1627. https://doi.org/10.3390/ nano11061627

Academic Editors: Frederik Tielens and Fabien Grasset

Received: 22 May 2021

Accepted: 17 June 2021

Published: 21 June 2021

Publisher's Note: MDPI stays neutral with regard to jurisdictional claims in published maps and institutional affiliations.

\begin{abstract}
Thermal insulation materials are highly sought after for applications such as building envelopes, refrigerators, cryogenic fuel storage chambers, and water supply piping. However, current insulation materials either do not provide sufficient insulation or are costly. A new class of insulation materials, hollow silica particles, has attracted tremendous attention due to its potential to provide a very high degree of thermal insulation. However, current synthesis strategies provide hollow silica particles at very low yields and at high cost, thus, making the particles unsuitable for real-world applications. In the present work, a synthesis process that produces hollow silica particles at very high yields and at a lower cost is presented. The effect of an infrared heat absorber, carbon black, on the thermal conductivity of hollow silica particles is also investigated and it is inferred that a carbon black-hollow silica particle mixture can be a better insulating material than hollow silica particles alone.
\end{abstract}

Keywords: silica; thermal insulation; hollow particles; energy; carbon black

\section{Introduction}

Thermal insulation materials are widely used in insulation applications, such as building envelopes, refrigerators, cryogenic storage of gases, water supply piping systems, high temperature fuel cells, thermal energy storage, heat exchangers, and combined heat and power systems [1-6]. Common thermal insulations include glass fiber, mineral wool, cellulose, extruded polystyrene (PS) foams, and polyurethane foams [7-10]. Their thermal conductivities range from 0.040 to $0.024 \mathrm{~W} / \mathrm{m} \cdot \mathrm{K}$ [7-10]. Higher thermal conductivity of these thermal insulation materials results in the need of a thick layer of material for achieving a sufficient amount of insulation [7-10]. A thick layer of insulation material means higher usage of material and space [7-10]. Silica aerogels are emerging insulation materials with a thermal conductivity of $\sim 0.014$ to $0.020 \mathrm{~W} / \mathrm{m} \cdot \mathrm{K}$ [11-16]. Unfortunately, aerogels are expensive, fragile, and hard to handle and lack scalability, hindering their widespread use [11-16]. Since aerogels have very low thermal conductivity, a thin layer of aerogels can provide the same amount of insulation that is obtained from a very thick layer of conventional insulation materials. Initially, pure silica aerogels were produced by using the sol-gel method [11-16]. Recently, several other types of aerogels, including carbon aerogels, graphene aerogels, carbon nanotube aerogels, and cellulose aerogels, have been produced [17-21].

A new type of insulation, hollow silica particles, is being explored as an alternative to aerogels. Hollow silica particles with a thermal conductivity of $\approx 0.02-0.03 \mathrm{~W} / \mathrm{m} \cdot \mathrm{K}$ have been reported [22-27]. These particles can be used alone as thermal insulation, or they can be mixed with other materials to form a hybrid thermal insulation material $[28,29]$. Note that other insulation materials (e.g., fibers, foams) will not lower the thermal conductivity 
of another material when mixed with it to form a hybrid insulation, rather they can increase the thermal conductivity of the hybrid material [30,31]. Therefore, hollow silica particles are a universal thermal insulation material that can be used alone or in combination with other materials (i.e., they make other materials better thermal insulators). It is the trapped air inside the cavities that gives hollow particles their low thermal conductivity, and it is mainly because of the cavities that these particles lower the thermal conductivity of any material in which they are mixed. In addition to use as thermal insulation, hollow silica particles are valuable for use in batteries, drug delivery, thermal energy storage, and several other applications [32-34].

Hollow silica particles can be synthesized by several methods, such as by using polymer micelles, reverse microemulsions, inorganic (e.g., calcium carbonate, carbon, hydroxy apatite) particles, polymer (e.g., polystyrene; PS) particles, and bacteria as templates [22-27,35-49]. Similarly, some other unconventional methods, including etching of solid silica particles and spray drying a solution of solid silica particles, have also been explored [50-53]. The use of PS particles as templates is the most widely used approach because PS particles can be synthesized at low cost and with tunable size [22-26]. PS particle-based synthesis of hollow silica particles involves three steps: (1) synthesizing PS particles, (2) depositing silica shells on PS particles, and (3) removing the PS cores by burning or dissolving them to obtain hollow silica particles [22-26]. There are only a few companies that sell hollow silica nanoparticles. Nittestu Mining Co., Ltd., (Tokyo, Japan) provides hollow silica nanoparticles (diameter $\approx 100 \mathrm{~nm}$, shell thickness $=5-15 \mathrm{~nm}$ ) under the brand name 'SiliNax' [54].

Although hollow silica particles have been reported for more than two decades and would be useful in several applications, their use in these applications is not commercially viable because of their high synthesis costs. The high cost results from the low synthesis yield and high wastage of solvents. For example, $100 \mathrm{~mL}$ of ethanol or isopropanol is used to make $\leq 3.0 \mathrm{~cm}^{3}$ of hollow silica particles [22-26]. The main barrier to high synthesis yields is the incomplete optimization of the synthesis reaction conditions.

In the present work, a very high yield $(\approx 25$ times the reported methods) synthesis of hollow silica particles, with minimal wastage of solvents resulting in low cost, is reported. The cost of hollow silica particles was lowered by two approaches: (1) by increasing the synthesis yield for the amount of solvent used, and (2) by recycling the solvents. Additionally, the effect of carbon black (CB; an infrared radiation absorber) on the thermal conductivity of hollow silica particles is investigated. Although the effect of adding CB on the thermal conductivity of silica aerogels has been studied, it has not been reported before for hollow silica particles [55-59]. Therefore, it was considered worth investigating, as hollow silica particles are a different class of materials from aerogels. Hollow silica particles are a powder, whereas aerogels are large slabs. When CB is added to hollow particles, it can affect the thermal conductivity in three different ways: (1) by absorbing radiative heat, (2) by increasing or decreasing the air volume in the system, and (3) by increasing the contact resistance at the particle interfaces. Although the radiative heat absorption effect (1) of CB is well known in other materials, effects (2) and (3) have not been investigated before [55-59].

The first part of this paper presents optimized conditions for hollow silica particle synthesis. The second part presents a novel strategy (recycling of solvents) to lower the manufacturing cost of hollow silica particles. The third part presents the effect of CB (a radiation absorber) on the thermal conductivity of hollow silica particle powder.

\section{Experimental}

\subsection{Chemicals}

Isopropanol, tetraethyl orthosilicate (TEOS), styrene, 2,2'-Azobis(2-methylpropionamidine) dihydrochloride, and ammonium hydroxide $\left(\mathrm{NH}_{4} \mathrm{OH}, 28-30 \%\right)$ were purchased from Sigma Aldrich (Burlington, MA, USA). 


\subsection{Polystyrene Particle Synthesis}

Polystyrene (PS) particles were synthesized by modifying a reported method [24]. In a typical synthesis, $100 \mathrm{~mL}$ water was heated at $60^{\circ} \mathrm{C}$ for $10 \mathrm{~min}$, followed by the addition of $5 \mathrm{~mL}$ of styrene to this hot water while stirring $(600 \mathrm{rpm})$ using a magnetic stir bar. The reaction mixture was allowed to stir for $1 \mathrm{~h}$ before adding $2 \mathrm{~mL}$ of $160 \mathrm{mg} / 1 \mathrm{~mL}$ of $2,2^{\prime}$-Azobis(2-methylpropionamidine) dihydrochloride. Then the reaction was allowed to stir for $12 \mathrm{~h}$. The synthesized particles were dried using an air blow drying oven and dried particles were further used as templates for the synthesis of hollow silica particles.

\subsection{Hollow Particle Synthesis}

To make hollow silica particles, in a typical experiment, $5.33 \mathrm{~g}$ of PS particles (an average diameter $300 \mathrm{~nm}$ ) were added into a solution having $100 \mathrm{~mL}$ of isopropanol, $30 \mathrm{~mL}$ water, and ammonium hydroxide ( $28-30 \%$; to make solution $\mathrm{pH} \approx 11)$. Then the reaction mixture was stirred for about $10 \mathrm{~min}$. In the second step, $4.5 \mathrm{~mL}$ of tetraethyl orthosilicate (TEOS) in 3 aliquots of $1.5 \mathrm{~mL}$ each separated by $4 \mathrm{~h}$ was added. TEOS can be added in a single step instead of in aliquots. The core-shell particles, being heavy, settled down and were easy to remove from the supernatant by decanting or centrifugation (used by us). The synthesized polystyrene core silica shell particles were dried using an air blow drying oven at $50{ }^{\circ} \mathrm{C}$. The dried core-shell particles were poured in a $300 \mathrm{~mL}$ crucible and were burned at $550{ }^{\circ} \mathrm{C}$ inside a Barnstead Thermolyne 47900 box furnace (Barnstead International, Dubuque, IA, USA) for $4 \mathrm{~h}$. The burning removed the polystyrene core, and pure hollow silica particles were collected after cooling to room temperature.

\subsection{SEM and TEM Studies}

Scanning electron microscope (SEM) imaging was done using a Merlin 200 instrument (ZEISS, Oberkochen, Germany) available in the Center for Nanophase Materials (a Department of Energy user facility). SEM samples were prepared by depositing polystyrene particle or hollow silica particle solutions in ethanol on silicon wafer pieces, which were then attached to the SEM stubs using double-sided carbon tape.

Transmission electron microscope (TEM) imaging was performed on a Hitachi HF3300 TEM/STEM (Hitachi Global, Chiyoda, Tokyo, Japan). Samples were prepared by dropping hollow particle solutions on lacey carbon coated copper TEM grids.

\subsection{Surface Area and Pore Size Measurements}

$\mathrm{N}_{2}$ gas adsorption and desorption measurements were performed using a Quantachrome TouchWin (Quantumchrome Instruments, Boynton Beach, FL, USA) instrument to determine the surface area and pore size distribution of the hollow silica particle sample. The Brunauer-Emmett-Teller (BET) analysis was used to determine the surface area from the adsorption data, whereas the pore size distribution was calculated via the density functional theory (DFT) model using the desorption data.

\subsection{Thermal Conductivity Measurements}

Thermal conductivity measurements were performed by using a transient plane source (TPS 2500 S) instrument and sensor C5465 (Hot Disc, Goteborg, Sweden). Sample holder provided by the manufacturer was used. No weight was placed on the samples, i.e., thermal conductivity measurements were done on loose particles without pressing.

\subsection{Solution Mixture Recycling}

During the synthesis of hollow particles, only $90 \%$ of TEOS is deposited on the polystyrene particles and the remaining $10 \%$ remains in the reaction mixture. Therefore, in each iteration, only $90 \%$ of the TEOS that is used in the first iteration was added (as shown below).

- $\quad$ 1st iteration: $100 \mathrm{~mL}$ solution:5 g PS particles:4.25 mL TEOS;

- 2nd iteration: $85 \mathrm{~mL}$ solution:4.25 g PS particles:3.25 mL TEOS; 
- 3rd iteration: $72 \mathrm{~mL}$ solution:3.60 g PS particles:2.75 mL TEOS.

\section{Results and Discussion}

\subsection{Hollow Silica Particle Synthesis with High Yield}

It was assumed that previous efforts to achieve high yields may have failed because very high concentrations of TEOS resulted in free silica particle formation as a side reaction. Therefore, the addition of TEOS in aliquots was chosen. Figure 1a shows a schematic demonstration of our approach of adding TEOS at specified time intervals to avoid reaching very high concentrations at any time in the reaction mixture, while adding sufficient total amounts to form shells around all the PS particles. Figure $1 \mathrm{~b}$ shows hollow particles obtained from $100 \mathrm{~mL}$ of isopropanol, Figure $1 \mathrm{c}$ is a scanning electron microscope (SEM) image, and Figure $1 \mathrm{~d}$ a transmission electron microscope (TEM) image of the obtained hollow silica particles.

a)
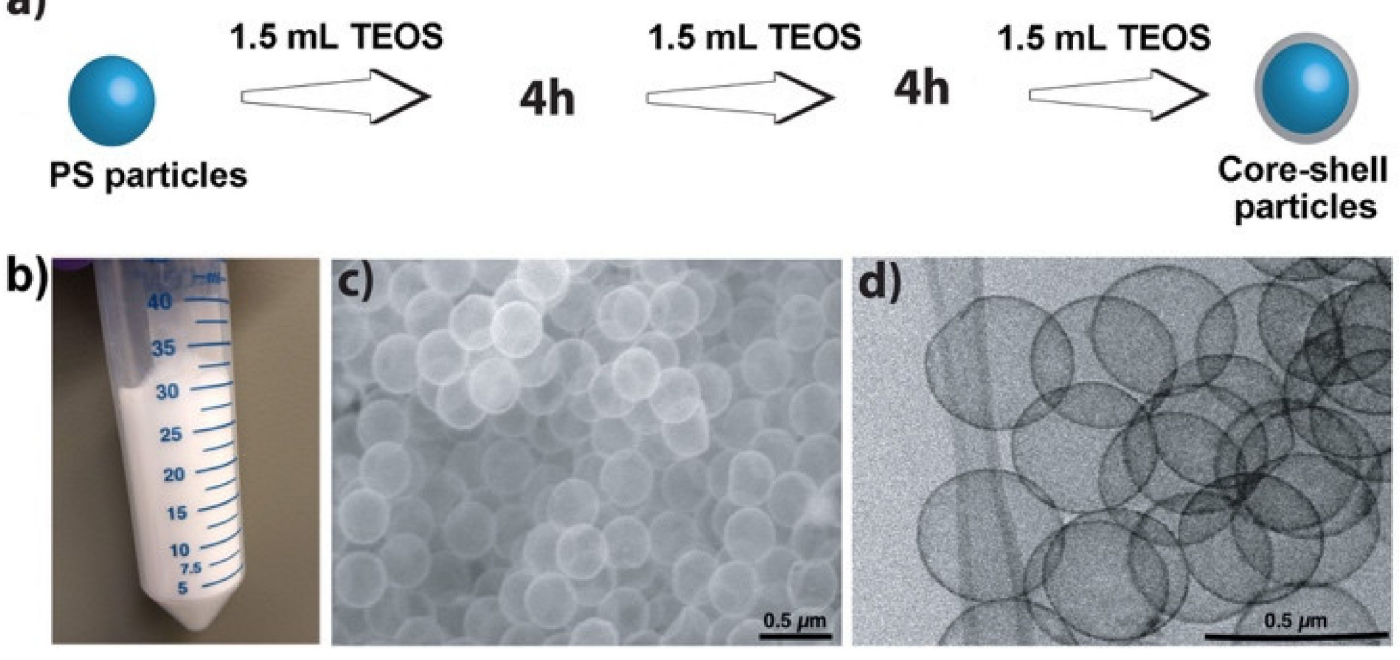

Figure 1. (a) Schematic showing the stepwise addition of TEOS at an optimum concentration to form silica shells around the PS particles at a high concentration. (b) Hollow particles synthesized from $100 \mathrm{~mL}$ of isopropanol. (c) SEM and (d) TEM images of the same hollow particles. Note: Schematic shows only the core-shell particle formation. The step of burning the PS cores to obtain hollow silica particles is not shown.

Efforts to further increase the reaction yield by increasing the amount of PS particles ( $>7.5 \mathrm{~g}$ particles $/ 100 \mathrm{~mL}$ of isopropanol) resulted in only partial shell formation on the PS particles. It was assumed that very high concentrations of PS particles increased the viscosity of the reaction mixture and, thus, hindered the uniform diffusion of TEOS. No hollow particles were formed when the isopropanol to water ratio was below 1.25. The best particles were obtained at an isopropanol/water ratio of 2.8-5.0. Note that high reaction yields can be obtained only when the reaction conditions, especially the reaction $\mathrm{pH}$ and TEOS amount, were fully optimized. When an insufficient amount of TEOS was added, incomplete shells were formed. Similarly, if the reaction $\mathrm{pH}$ was lower than 9.5, small free silica nanoparticles $(\approx 2-10 \mathrm{~nm})$ were formed. Therefore, for adequate shell formation and high yields, the $\mathrm{pH}$ should be higher than 9.5 (optimal $\mathrm{pH}$ range: 10.5-11.5) (Figure 2). TEOS was added at $4 \mathrm{~h}$ time intervals so that a sufficient amount of previously added TEOS can be consumed [59]. The TEOS aliquots can be added at intervals of more than $4 \mathrm{~h}$ but less than $10 \mathrm{~h}$. It was observed that if the intervals were increased beyond $10 \mathrm{~h}$, the ammonium hydroxide concentration decreased and the consumption of TEOS after subsequent aliquot additions became very slow. It was observed that the method of addition (single step or in aliquots) did not affect the final outcome of hollow silica particle formation, i.e., both methods provided the same type of particles. It was the reaction $\mathrm{pH}$ that controlled the shell formation. Well-formed silica shells were obtained only in a pH range of 10.5-11.5. 


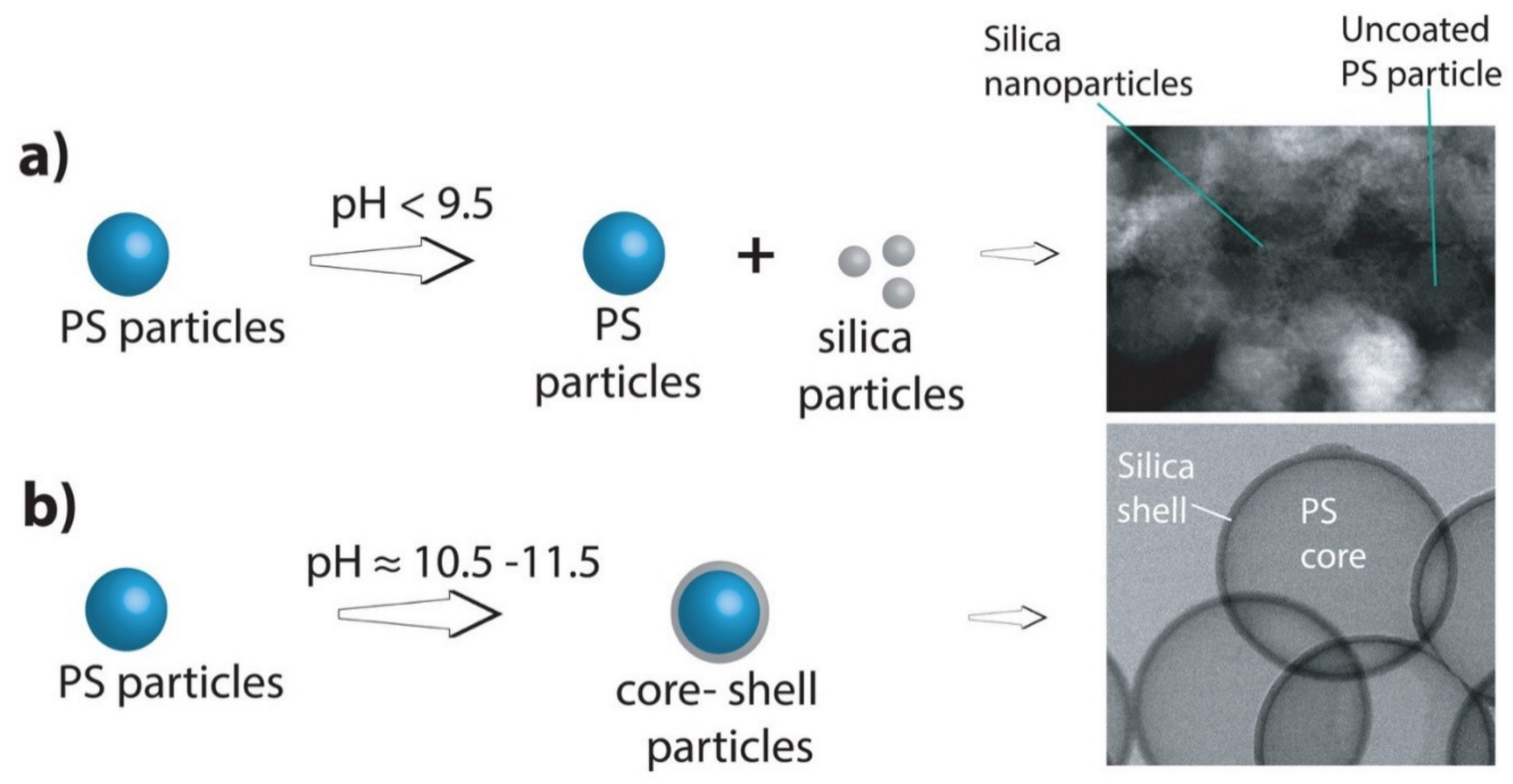

Figure 2. (a) (Left) schematic depiction of shell formation outcome when $\mathrm{pH}$ is below 9.5; (right) TEM image showing bare PS particles and free silica nanoparticles formed in the process. (b) Schematic depiction of shell formation outcome when $\mathrm{pH}$ is $\approx 11$ and STEM image showing nicely formed PS core silica shell particles without any free silica particle formation. Note: Schematics show only core-shell particle formation. The step of burning the PS cores to obtain hollow silica particles is not shown.

\subsection{Cost Reduction of Hollow Silica Particle Manufacturing Process}

To further lower the synthesis cost, for the first time, recycling of the reaction solution was demonstrated. After the shell formation, the core-shell particles settled down at the bottom of the reaction mixture container, and could be easily separated from the supernatant reaction mixture either by decantation or centrifugation (used in this work). After the core-shell particles were collected by centrifugation, the supernatant was used again to synthesize the next batch of core-shell particles by bringing the $\mathrm{pH}$ back to 11 (any value $>10.5$ gives similar results). It was observed that the $\mathrm{pH}$ had dropped from 11 to $\approx 9.0$ by the end of the synthesis cycle, thus, the $\mathrm{pH}$ of the supernatant after a synthesis cycle was always lower than that of the initial reaction mixture. The reduction in the $\mathrm{pH}$ resulted from (1) evaporation and (2) consumption of ammonia as the reaction proceeded. About $85 \%$ of the solution was retrieved at each step via centrifugation, although it was noted that up to $\approx 95 \%$ of the solution could be retrieved. The centrifugation and supernatant use cycle was repeated three times. In each step, the amounts of PS particles and TEOS were varied to make the proportional amounts the same as in the original reaction mixture. SEM imaging showed that the quality of the particles synthesized remained the same in all iterations. Therefore, the entire process was highly useful for increasing the amount of hollow particles obtained without wasting solvent and, thus, for lowering the process cost.

Using the same $100 \mathrm{~mL}$ solvent (isopropanol), approximately $75 \mathrm{~cm}^{3}$ of hollow silica particles were obtained, and the supernatant could still be used to synthesize the next batch of particles. Note that previously reported methods provide less than $3 \mathrm{~cm}^{3}$ of hollow silica particles $/ 100 \mathrm{~mL}$ of solvent [22-26]. Therefore, our approach provided $\approx 25$ times more hollow silica particles for the same amount of solvent if the solvent was recycled three times. However, it was calculated that, assuming $85 \%$ reaction solution recovery after each iteration (a conservative estimate, as $95 \%$ of the solution can be recovered) and extrapolating the number of iterations to six (after which the amount of reaction solution drops to about $50 \mathrm{~mL}$ ), about $125 \mathrm{~cm}^{3}$ (40 times more than the previously reported methods) of particles can be obtained from the same reaction mixture $(100 \mathrm{~mL}$ isopropanol $+30 \mathrm{~mL}$ water) just by adjusting the $\mathrm{pH}$ and adding additional TEOS. Figure 3a shows the schematic 
of reaction solution recycling, and Figure $3 \mathrm{~b}-\mathrm{d}$ are SEM images of hollow particles obtained from the original synthesis cycle, the first iteration, and the second iteration, respectively.
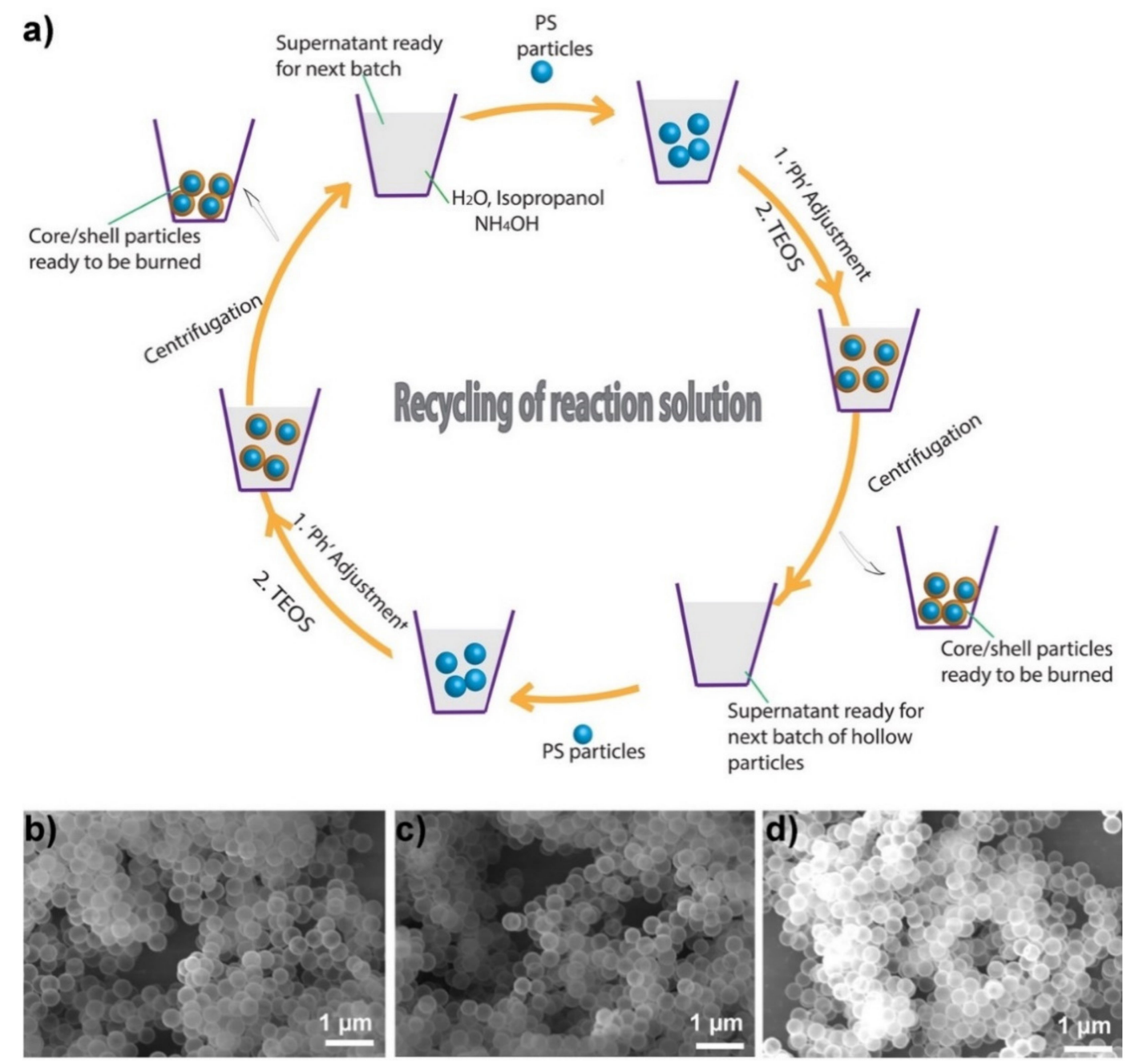

Figure 3. Recycling of the reaction solution. (a) Schematic showing the recycling steps. SEM images of the particles synthesized by (b) the original reaction mixture, (c) the first reiteration, and (d) the second reiteration. Note: The process was repeated only three times in this work, but the retrieved solution can be used for several more reiterations as long as the $\mathrm{pH}$ is maintained.

In a similar approach, it was observed that the reaction mixture can be used endlessly by adding additional fresh solvents (isopropanol + water) and adjusting the $\mathrm{pH}$, while making the volume of the final reaction mixture equal to the original volume. The solution recycling can be repeated as long as the solution is free of any TEOS oligomers remaining from a previous batch. TEOS oligomers remaining in the retrieved solution can make the particles of the subsequent batch somewhat rough as a result of large nanograin formation. The shell formation process involves, initially, the formation of small silica nanograins (oligomers), which then attach to the PS surface to make the contiguous silica shell. To avoid the presence of any TEOS oligomers or small silica nanograins, the reaction was allowed to proceed for $12 \mathrm{~h}$ after the addition of the last aliquot of TEOS. The longer reaction time ensured that all TEOS was consumed [60]. Additionally, centrifugation was employed to ensure the removal of any remaining silica nanograins. High-resolution TEM/energy-dispersive $X$-ray spectroscopy imaging further confirmed the absence of any small nanograins in the retrieved supernatant solution used for subsequent hollow particle synthesis cycles. 


\subsection{Cost Analysis}

To estimate synthesis costs, the costs of the amounts of different chemicals used in this work were compared with the extrapolated amounts of chemicals that will be used in the reported works to obtain the $1 \mathrm{ft}^{2} \times 1 \mathrm{~cm}$ of particles [22-26]. Table 1 illustrates an estimated cost analysis of hollow particle synthesis. Cost estimates show that $1 \mathrm{ft}^{2} \times 1 \mathrm{~cm}$ particles can be obtained at a cost of USD 1.30 by using ORNL strategy while reported methods will provide the same amount of particles at a cost of $\approx$ USD 15 . For cost analysis purposes, $130 \mathrm{~g}$ of polystyrene particles can be added to $2860 \mathrm{~mL}$ of solution $(2000 \mathrm{~mL}$ isopropanol or ethanol $+860 \mathrm{~mL}$ water), followed by the addition of ammonium hydroxide and $110 \mathrm{~mL}$ of TEOS. After silica shell formation, $\approx 2450 \mathrm{~mL}$ of solution $(\approx 1700 \mathrm{~mL}$ of isopropanol or ethanol) can be retrieved. Therefore, only $300 \mathrm{~mL}$ of isopropanol or ethanol will be lost by using ORNL synthesis strategy. Because the reported synthesis strategies provide a very small amount $\left(\approx 3 \mathrm{~cm}^{3}\right)$ of particles for $100 \mathrm{~mL}$ of alcohol, approximately $15 \mathrm{~L}$ of alcohol will be used for obtaining the same amount of particles.

Table 1. Cost analysis of ORNL hollow silica particle manufacturing process compared with the currently reported processes [22-26].

\begin{tabular}{|c|c|c|c|c|c|}
\hline \multirow{2}{*}{ Item } & \multirow{2}{*}{ Unit Price (USD) } & \multicolumn{2}{|c|}{ Required Amount ${ }^{a}$} & \multicolumn{2}{|c|}{ Cost (USD) ${ }^{a}$} \\
\hline & & ORNL & Reported $^{\text {b }}[22-26]$ & ORNL & Reported \\
\hline Styrene & $1.5 / 1.1 \mathrm{~L}$ & $200 \mathrm{~mL}$ & $200 \mathrm{~mL}$ & 0.3 & 0.3 \\
\hline Catalyst & $5 / \mathrm{kg}$ & $5 \mathrm{~g}$ & $5 \mathrm{~g}$ & 0.03 & 0.03 \\
\hline Alcohol (ethanol/isopropanol) & $0.9 / \mathrm{L}$ & $300 \mathrm{~mL}$ & $15 \mathrm{~L}$ & 0.27 & 13.5 \\
\hline Ammonium hydroxide & $0.50 / \mathrm{L}$ & $25 \mathrm{~mL}$ & $1.25 \mathrm{~L}$ & 0.0125 & 0.625 \\
\hline Tetraethyl orthosilicate & $1.9 / \mathrm{L}$ & $100 \mathrm{~mL}$ & $100 \mathrm{~mL}$ & 0.20 & 0.19 \\
\hline Electricity & $0.10 / \mathrm{kWh}$ & $5 \mathrm{kWh}$ & $5 \mathrm{kWh}$ & $0.50^{\mathrm{d}}$ & 0.50 \\
\hline Total manufacturing cost ${ }^{\mathrm{c}}$ & & & & 1.31 & 15.14 \\
\hline
\end{tabular}

${ }^{a}$ Values are based on a sample volume equivalent to $1 \mathrm{ft}^{2} \times 1 \mathrm{~cm},{ }^{b}$ Reported amounts of chemicals ae estimated by extrapolating the amounts of different chemicals to get $1 \mathrm{ft}^{2} \times 1 \mathrm{~cm}$ from references [22-26], ${ }^{\mathrm{c}}$ Does not include labor, ${ }^{\mathrm{d}}$ Electricity consumption will be lower in ORNL strategy because of high initial yield, however we included similar costs for both manufacturing processes.

By looking at the cost analysis table (Table 1), it is clear the costs of all other chemicals except the solvent are almost same in both strategies, and the cost of the solvent is the main contributing factor in the final cost of hollow particles. Our strategy reduced the amount of solvent used by recycling it and, thus, substantially lowered the manufacturing cost of hollow particles.

\subsection{Effect of Carbon Black (CB) on the Thermal Conductivity of Hollow Particles}

Additionally, the effect of $\mathrm{CB}$ addition on the thermal conductivity of hollow silica particles was investigated. The thermal conductivity of the original particles depended upon the shell thickness, cavity size, shell quality, and whether any solid silica particle debris was present in the sample. For CB effect experiments, particles with a diameter of $300-325 \mathrm{~nm}$, a shell thickness of about 6-12 nm, and internal cavity size of 285-310 nm were selected. Brunauer-Emmett-Teller (BET) analysis showed that hollow particles had a surface area of $\approx 115 \pm 8 \mathrm{~m}^{2} / \mathrm{g}$. A large portion of pores in the shell were microporous $(<2 \mathrm{~nm})$. Additionally, mesopores of varying sizes (large portion with 2-10 nm size and a very small portion with 2-20 nm size) were also observed. Figure 4 shows the (a) $\mathrm{N}_{2}$ adsorption-desorption isotherms and (b) the extracted pore size distributions of the $\mathrm{SiO}_{2}$ sample by using density functional theory (DFT).

The thermal conductivity of the hollow particles decreased at additions of up to approximately $20 \mathrm{wt} \%$ of $\mathrm{CB}$ and then began increasing (Figure 5). From the plot in Figure 5, it can be seen that the thermal conductivity drop is sharp in the beginning, and the decrease 
in thermal conductivity is more $(0.0230$ to $0.0221 \mathrm{~W} / \mathrm{m} \cdot \mathrm{K})$, from $5 \mathrm{wt} \%$ to $10 \mathrm{wt} \% \mathrm{CB}$ addition. The thermal conductivity decreased less $(0.0214$ to $0.0210 \mathrm{~W} / \mathrm{m} \cdot \mathrm{K})$, from $15 \mathrm{wt} \%$ to $20 \mathrm{wt} \%$ CB. It appeared that in the initial stages, the addition of carbon black resulted in radiative heat absorption and, thus, showed a big decrease in thermal conductivity. In the later stages (15 wt\% to $20 \mathrm{wt} \%$ ), it seemed the sample got saturated with carbon black, and radiative heat absorption effect decreased and bottomed at $20 \mathrm{wt} \% \mathrm{CB}$ addition. Beyond $20 \mathrm{wt} \%$, further addition of CB may have resulted in the saturation of hollow particle sample, and no additional radiative heat absorption effect occurred. Instead of decreasing the thermal conductivity, the CB addition increased the thermal conductivity beyond $20 \mathrm{wt} \%$ due to pronounced effect of conductive heat transfer through carbon black particles. It must be noted, CB has been used for both decreasing the thermal conductivity (due to radiative heat absorption) and for increasing the thermal conductivity (due to increased conductive heat transfer) in different composite materials [55-59,61,62]. The effect of thermal conductivity can change (shape of plot, sharp or slow decline) from experiment to experiment, depending upon the degree of dispersibility, however, the trend (first decrease in thermal conductivity and then increase in thermal conductivity) remains the same.

a)

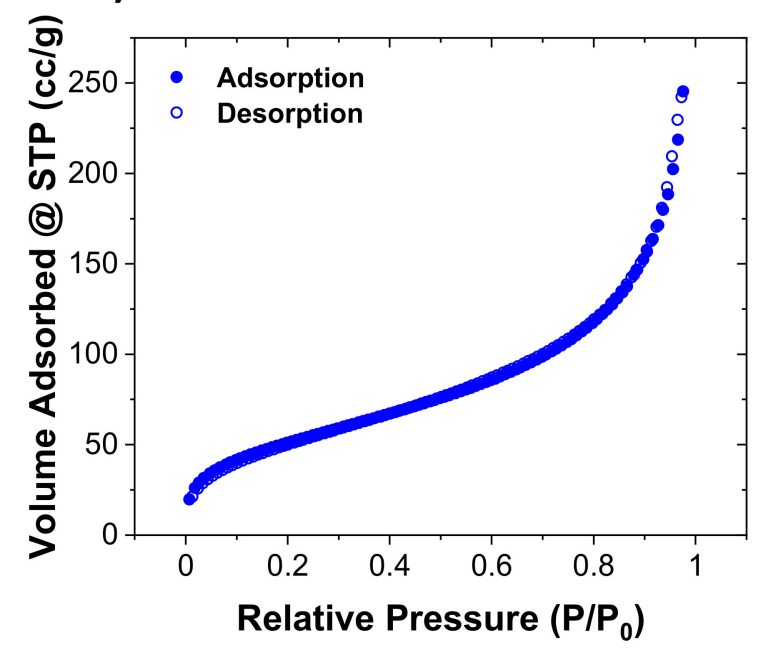

b)

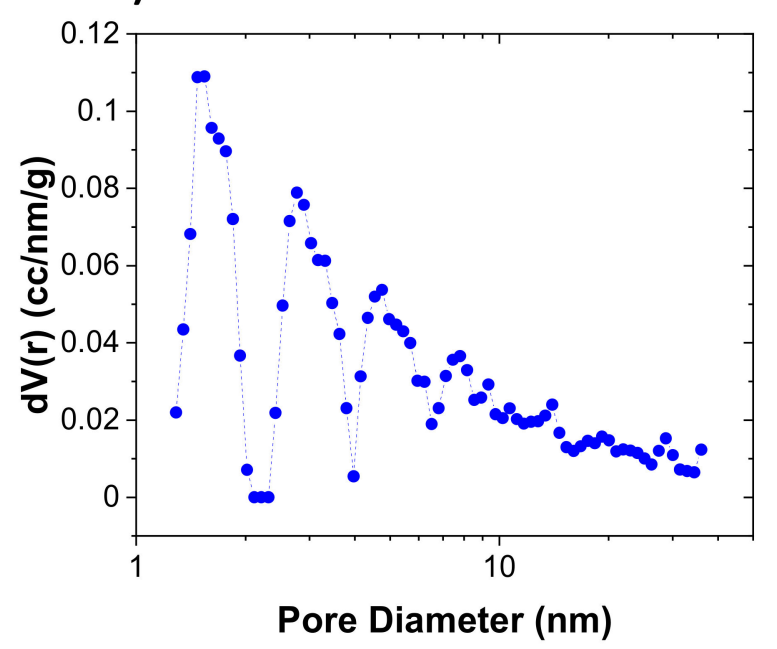

Figure 4. Surface area and pore size distribution measurements of a hollow silica particle sample by using $\mathrm{N}_{2}$ adsorptiondesorption isotherms and density functional theory (DFT). (a) $\mathrm{N}_{2}$ adsorption-desorption isotherms and (b) the extracted pore size distributions of the $\mathrm{SiO}_{2}$ sample by using density functional theory (DFT).

In aerogels, $\mathrm{CB}$ is known to lower the thermal conductivity by absorbing radiative energy, i.e., by mitigating the radiative heat transfer [55-59]. However, in powdered materials, other factors, such as a change in the air volume of the sample and increased contact resistance, can also play an important role. For example, in one experiment, a known volume $\left(0.16 \mathrm{~cm}^{3}\right)$ of CB to a known volume $\left(0.8 \mathrm{~cm}^{3}\right)$ of hollow particles. To our surprise, the combined volume $\left(1.2 \mathrm{~cm}^{3}\right)$ of $\mathrm{CB}$ and hollow particles was more than the sum of their individual volumes $\left(0.96 \mathrm{~cm}^{3}\right)$. Therefore, it was assumed that not only the absorption of radiative energy, but also an increase in the total air volume of the system, can contribute to lowering the thermal conductivity of a hollow silica particle and CB mixture. It is worth mentioning that hollow or porous materials have low thermal conductivity due to the air (thermal conductivity $\approx 0.024 \mathrm{~W} / \mathrm{m} \cdot \mathrm{K}$ ) inside their cavities or pores. Any increase in air volume generally results in a corresponding decrease in the thermal conductivity of a material. It appears that the increase in total volume resulted from the intercalation of CB nanoparticles between hollow particles and, thus, from the increased spacing between the hollow particles. Photographs of samples used for measuring the volumes of $C B$, hollow silica particles, and the combined sample are provided in Figure 6 (B, B', \& B"). Additionally, in aerogels, the lowest obtainable thermal conductivity was obtained by 
adding a small amount $(\approx 10 \mathrm{wt} \%)$ of $\mathrm{CB}$, whereas in hollow particles, the lowest thermal conductivity was achieved at quite a high amount $(20 \mathrm{wt} \%$ ) of CB (similar to the case for powdered aerogels) $[55,58,59]$. The difference in the results arises from the differences in the microstructures of aerogels (monolithic, consisting of 2-5 nm nanoparticles) and hollow particles (particulate, larger particle size), and from other factors. Radiative absorption plays the main role in the conductivity of aerogels, whereas increased air volume and contact resistance, along with radiative absorption, may affect the thermal properties of a CB-hollow particle mixture.

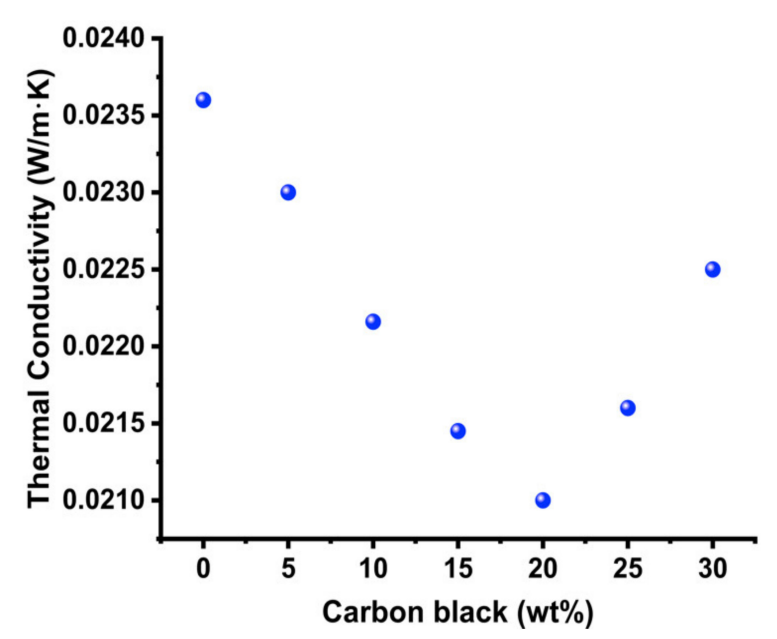

Figure 5. Plot showing how adding different amounts of $\mathrm{CB}$ affects the thermal conductivity of hollow silica particles.

To understand how CB dispersion affects the thermal conductivity of a CB-hollow particle mixture, another sample ' $C$ ', in which the only difference was the method of $C B$ dispersion, was created. In sample ' $\mathrm{B}$ ', the $\mathrm{CB}$ was dispersed mechanically by shaking the sample without adding any solvent. In sample ' $\mathrm{C}$ ', ethanol was added and the sample was sonicated, followed by drying. Figure 7 bar chart shows the effect of the $\mathrm{CB}$ dispersion method on the thermal conductivity of hollow particle CB sample. The thermal conductivity of sample ' $\mathrm{C}$ ' (CB dispersed by sonication) was $19.5 \mathrm{~W} / \mathrm{m} \cdot \mathrm{K}$, lower than the 20.5 $\mathrm{W} / \mathrm{m} \cdot \mathrm{K}$ conductivity of sample ' $\mathrm{B}$ ' (CB dispersed by mechanical mixing). Insets $\mathrm{i}-\mathrm{iii}$ of Figure 7, respectively, correspond to SEM images of the hollow particles alone, mechanically mixed sample ' $B$ ', and sample ' $C$ ', mixed by sonication. Big chunks of $C B$ appear in the mechanically mixed sample (inset ii), while small CB chunks are seen in the sample mixed by sonication (inset iii). Similarly, corresponding sub-inset photos clearly show that mechanical mixing did not disperse the $\mathrm{CB}$ completely, but sonication in ethanol resulted in better dispersion.

The improvement in thermal conductivity resulting from better dispersion of $\mathrm{CB}$ seems due to an increased number of interfaces between the $\mathrm{CB}$ and the hollow particles. It is known that an increase in the number of interfaces can increase the total contact resistance (or Kapitza resistance) of a sample [63]. This experiment indicates that more thorough CB dispersion increased the contact resistance by increasing the number of silica- $\mathrm{CB}$ interfaces, which helped further lower the thermal conductivity of the mixture. Since the CB amount is the same in both cases, it was assumed that radiative heat absorption is the same in both cases. Therefore, it appears that a combination of factors-increased air volume, increased contact resistance, and increased radiative absorption-lowered the thermal conductivity of the hollow particle-CB mixture. Among all these factors, it seems that the increased contact resistance had a more prominent effect than the increased air volume, because the sonicated sample ' $C$ ' had a smaller final volume (samples $C, C$ ', \& $C$ " in Figure 6), but lower thermal conductivity. 

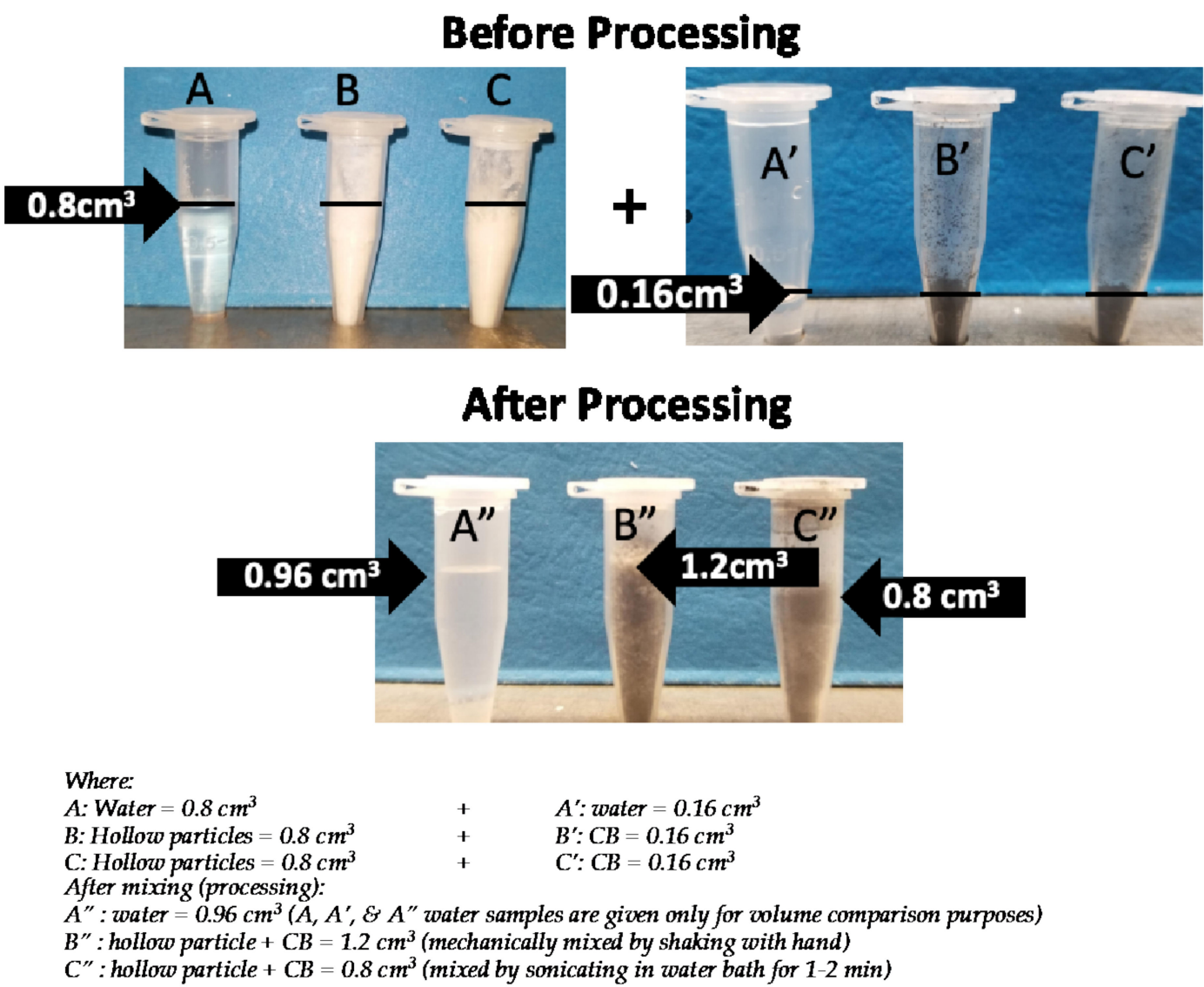

Figure 6. Digital photographs of different samples (hollow particles and carbon black) used in the CB effect on hollow particle thermal conductivity studies. Additionally, amounts of different samples are given in the lower part of the figure.

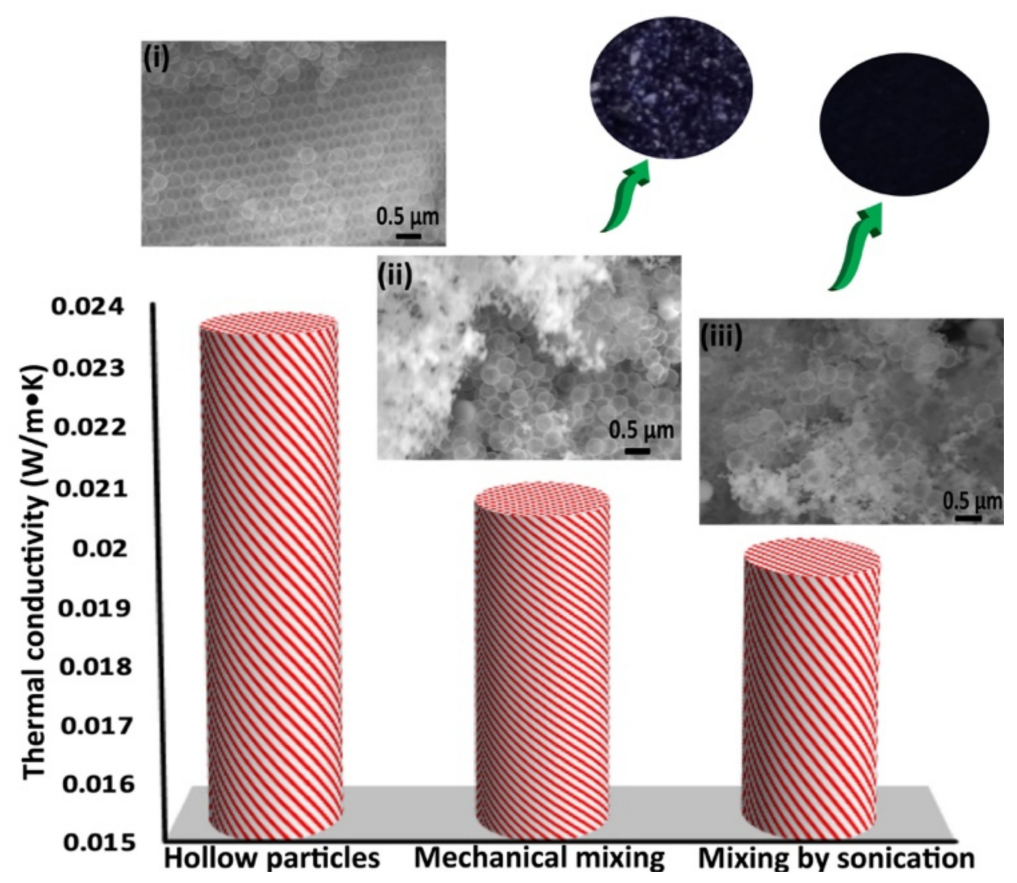

Figure 7. A plot showing the effect of CB dispersion on the thermal conductivity of a hollow particlecarbon black mixture. Insets (i), (ii), and (iii) are SEM images of hollow particles alone, a mechanically mixed hollow particle-CB mixture, and an ultrasonically mixed hollow particle-CB mixture, respectively. Sub-insets: Photos of mechanically and ultrasonically mixed CB and hollow particles. 


\section{Conclusions}

A synthesis strategy that can provide very high yields of hollow silica particles compared with previously reported methods was demonstrated. The critical requirement for a high synthesis yield was to control the reaction $\mathrm{pH}$ and the amount of silica precursor. For the first time, the recycling of the reaction solution, which further lowers the synthesis cost of the hollow silica particles, was also demonstrated. Additionally, it was found that good dispersion of $\mathrm{CB}$ is critical to achieve the maximum reduction in the thermal conductivity of the powdered material. It is anticipated that this work will open opportunities for a number of applications requiring large amounts of inexpensive hollow silica particles. Additionally, the recycling of reaction solutions can be applied in other similar particle synthesis strategies. The findings regarding the addition of $C B$ open new avenues to investigate the effects of opacifiers on powdered materials. They include new effects that may be related to an increase in air volume and contact resistance, which were not considered in previous studies.

Author Contributions: Conceptualization, J.S.; methodology, J.S. and G.P.; formal analysis, J.S., G.P., D.S., D.A.C. and N.M.; investigation, N.M. and J.S.; resources, J.S.; writing - original draft preparation, D.S. and J.S.; writing - review and editing, J.S. and G.P.; supervision, J.S.; project administration, J.S.; funding acquisition, J.S. All authors have read and agreed to the published version of the manuscript.

Funding: This research was supported by the DOE Office of Energy Efficiency and Renewable Energy, Building Technologies Office, under grants BT0301000 and BT0304020 to J.S.

Acknowledgments: Oak Ridge National Laboratory (ORNL) is managed by UT-Battelle LLC for the US Department of Energy. A portion of this research used resources at the Building Technologies Research and Integration Center and the Center for Nanophase Materials Sciences, both DOE Office of Science User Facilities operated by ORNL. We are thankful to Charl J. Jafta from ORNL for his help in performing the surface area and pore size measurement studies.

Conflicts of Interest: Authors declare no conflict of interest.

\section{References}

1. Jelle, B.P. Traditional, state-of-the-art and future thermal building insulation materials and solutions-Properties, requirements and possibilities. Energy Build. 2011, 43, 2549-2563. [CrossRef]

2. Engels, H.-W.; Pirkl, H.-G.; Albers, R.; Albach, R.W.; Krause, J.; Hoffmann, A.; Casselmann, H.; Dormish, J. Polyurethanes: Versatile materials and sustainable problem solvers for today's challenges. Angew. Chem. Int. Ed. 2013, 52, 9422-9441. [CrossRef]

3. Berge, A.; Adl-Zarrabi, B.; Hagentoft, C.-E. Assessing the thermal performance of district heating twin pipes with vacuum insulation panels. Energy Procedia 2015, 78, 382-387. [CrossRef]

4. Zhang, J.; Fisher, T.S.; Ramachandran, P.V.; Gore, J.P.; Mudawar, I. A review of heat transfer issues in hydrogen storage technologies. J. Heat Transf. 2005, 127, 1391-1399. [CrossRef]

5. Navalho, J.E.P.; Pereira, J.M.C.; Pereira, C.F. A methodology for thermal analysis of complex integrated systems: Application to a micro-CHP plant. Appl. Therm. Eng. 2017, 112, 1510-1522. [CrossRef]

6. Hu, F.; Wu, S.; Sun, Y. Hollow-structured materials for thermal insulation. Adv. Mater. 2019, 31, 1801001-1801017. [CrossRef] [PubMed]

7. Wicklen, B.; Kocjan, A.; Carosio, F.; Camino, G.; Antonitti, M.; Bergstrom, L. Thermally insulating and fire-retardant lightweight anisotropic foams based on nanocellulose and graphene oxide. Nat. Nanotechnol. 2015, 10, 277-283. [CrossRef] [PubMed]

8. Yu, Z.-L.; Yang, N.; Apostolopoulou-Kalkavoura, V.; Qin, B.; Ma, Z.-Y.; Xing, W.-Y.; Qiao, C.; Bergstrcm, L.; Antonietti, M.; Yu, S.-H. Fire-Retardant and Thermally Insulating Phenolic-Silica Aerogels. Angew. Chem. Int. Ed. 2018, 57, 4538-4542. [CrossRef] [PubMed]

9. Zhao, S.; Malfait, W.J.; Guerrero-Alburquerque, N.; Koebel, N.M.; Nystrcm, G. Biopolymer aerogels and foams: Chemistry, properties, and applications. Angew. Chem. Int. Ed. 2018, 57, 7580-7608. [CrossRef] [PubMed]

10. Asdrubali, F.; D'Alessandro, F.; Schiavoni, S. A review of unconventional sustainable building insulation materials. Sustain. Mater. Technol. 2015, 4, 1-17. [CrossRef]

11. Gurav, J.L.; Jung, I.-K.; Park, H.-H.; Kang, E.S.; Nadargi, D.Y. Silica aerogel: Synthesis and applications. J. Nanomater. 2010, 2010. [CrossRef]

12. Pierre, A.C.; Pajonk, G.M. Chemistry of aerogels and their applications. Chem. Rev. 2002, 102, 4243-4265. [CrossRef]

13. Wang, J.; Petit, D.; Ren, S. Transparent thermal insulation silica aerogels. Nanoscale Adv. 2020, 2, 5504-5515. [CrossRef]

14. Lamy-mendes, A.; Dora, A.; Pontinha, R.; Alves, P.; Santos, P.; Durães, L. Progress in silica aerogel-containing materials for buildings' thermal insulation. Constr. Build. Mater. 2021, 286, 122815. [CrossRef] 
15. Zhao, S.; Siqueira, G.; Drdova, S.; Norris, D.; Ubert, C.; Bonnin, A.; Galmarini, S.; Ganobjak, M.; Pan, Z.; Brunner, S.; et al. Additive manufacturing of silica aerogels. Nature 2020, 584, 387-392. [CrossRef]

16. Ma, H.; Zheng, X.; Luo, X.; Yi, Y.; Yang, F. Simulation and analysis of mechanical properties of silica aerogels: From rationalization to prediction. Materials 2018, 11, 214. [CrossRef]

17. Zhao, D.; Yu, L.; Liu, D. Ultralight graphene/carbon nanotubes aerogels with compressibility and oil absorption properties Materials 2018, 11, 641. [CrossRef]

18. Lin-Yu Long, L.-Y.; Weng, Y.-X.; Wang, Y.-Z. Cellulose aerogels: Synthesis, applications, and prospects. Polymers 2018, 10, 623. [CrossRef]

19. Illera, D.; Mesa, J.; Gomez, H.; Maury, H. Cellulose aerogels for thermal insulation in buildings: Trends and challenges. Coatings 2018, 8, 345. [CrossRef]

20. Chen, C.; Hu, L. Super elastic and thermally insulating carbon aerogel: Go tubular like polar bear hair. Matter 2019, 1, 36-38. [CrossRef]

21. Sroysee, W.; Suktha, P.; Kongsawatvoragu, K.; Vadivel, S.; Sawangphruk, M. Graphene aerogels with ultrahigh pore volume for organic dye adsorption and high-energy lithium batteries. Ind. Eng. Chem. Res. 2020, 59, 20719-20729. [CrossRef]

22. Gao, T.; Jelle, B.P.; Sandberg, L.I.; Gustavsen, A. Monodisperse Hollow Silica Nanospheres for Nano Insulation Materials: Synthesis, Characterization, and Life Cycle Assessment. ACS Appl. Mater. Interfaces 2013, 5, 761-767. [CrossRef]

23. Sandberg, L.I.C.; Gao, T.; Jelle, B.P.; Gustavsen, A. Synthesis of hollow silica nanospheres by sacrificial polystyrene templates for thermal insulation applications. Adv. Mater. Sci. Eng. 2013. [CrossRef]

24. Nandiyanto, A.B.D.; Akane, Y.; Ogi, T.; Okuyama, K. Mesopore-free hollow silica particles with controllable diameter and shell thickness via additive-free synthesis. Langmuir 2012, 28, 8616-8624. [CrossRef]

25. Liao, Y.; Wu, X.; Liu, H.; Chen, Y. Thermal conductivity of powder silica hollow spheres. Thermochim. Acta 2011, 526, 178-184 [CrossRef]

26. Wu, X.; Tian, Y.; Cui, Y.; Wei, L.; Wang, Q.; Chen, Y. Raspberry-like silica hollow spheres: Hierarchical structures by dual latex-surfactant templating route. J. Phys. Chem. C 2007, 111, 9704-9708. [CrossRef]

27. Sharma, J.; Polizos, G. Hollow Silica Particles: Recent Progress and Future Perspectives. Nanomaterials 2020, 10, 1599. [CrossRef]

28. Ernawati, L.; Ogi, T.; Balgis, R.; Okuyama, K.; Stucki, M.; Hess, S.C.; Stark, W.J. Hollow silica as an optically transparent and thermally insulating polymer additive. Langmuir 2016, 32, 338-345. [CrossRef] [PubMed]

29. Liao, Y.; Wu, X.; Wang, Z.; Yue, R.; Liu, G.; Chen, Y. Composite thin film of silica hollow spheres and waterborne polyurethane: Excellent thermal insulation and light transmission performances. Mater. Chem. Phys. 2012, 133, 642-648. [CrossRef]

30. Vaggar, G.B.; Kamate, S.C.; Badyankal, P.V. Thermal properties characterization of glass fiber hybrid polymer composite materials. Int. J. Eng. Technol. 2018, 7, 455-458. [CrossRef]

31. Zhao, Y.-H.; Zhang, Y.-F.; Wu, Z.-K.; Bai, S.-L. Synergic enhancement of thermal properties of polymer composites by graphene foam and carbon black. Compos. Part B Eng. 2016, 84, 52-58. [CrossRef]

32. Cao, X.; Chuan, X.; Li, S.; Huang, D.; Cao, G. Hollow silica spheres embedded in a porous carbon matrix and its superior performance as the anode for lithium-ion batteries. Part. Part. Syst. Charact. 2016, 33, 110-117. [CrossRef]

33. Li, Y.; Li, N.; Pan, W.; Yu, Z.; Yang, L.; Tang, B. Hollow mesoporous silica nanoparticles with tunable structures for controlled drug delivery. ACS Appl. Mater. Interfaces 2017, 9, 2123-2129. [CrossRef] [PubMed]

34. Fan, F.; Gao, H.; Dong, W.; Tang, J.; Wang, J.; Yang, M.; Wang, G. Shape-stabilized phase change materials based on stearic acid and mesoporous hollow $\mathrm{SiO}_{2}$ microspheres $\left(\mathrm{SA} / \mathrm{SiO}_{2}\right)$ for thermal energy storage. Eur. J. Inorg. Chem. 2017, 2017, $2138-2143$. [CrossRef]

35. Horikoshi, S.; Akao, Y.; Ogura, T.; Sakai, H.; Abe, M.; Serpone, N. On the stability of surfactant-free water-in-oil emulsions and synthesis of hollow SiO2 nanospheres. Colloids Surf. Physicochem. Eng. Asp. 2010, 372, 55-60. [CrossRef]

36. Hwang, H.S.; Bae, J.H.; Park, I.; Park, J.M.; Lim, K.T. Fabrication of hollow silica particles using copolymeric spheres prepared in supercritical carbon dioxide. J. Supercrit. Fluids 2009, 50, 292-296. [CrossRef]

37. Meng, Q.; Wang, K.; Xu, X.; Tang, Y.; Han, Z.; Zhao, K.; Zhang, G.; Cui, J.; Ji, Y. Synthesis of hollow silica particles using acid dissolvable resorcinol-formaldehyde resin particles as template. Chem. Sel. 2018, 3, 8919-8925. [CrossRef]

38. Chen, Y.; Wang, Y. Synthesis and characterization of hollow mesoporous silica spheres using negative-charged polystyrene particles as templates. J. Inorg. Organomet. Polym. Mater. 2017, 27, 380-384. [CrossRef]

39. Hu, W.; Gu, H.; Wang, J.; Li, Y.; Wang, Z. One-step synthesis of silica hollow particles in a W/O inverse emulsion. Colloid Polym. Sci. 2013, 291, 2697-2704. [CrossRef]

40. Nomura, T.; Morimoto, Y.; Tokumoto, H.; Konishi, Y. Fabrication of silica hollow particles using Escherichia coli as a template. Mater. Lett. 2008, 62, 3727-3729. [CrossRef]

41. Sasidharan, M.; Nakashima, K. Core-shell-corona polymeric micelles as a versatile template for synthesis of inorganic hollow nanospheres. Acc. Chem. Res. 2014, 47, 157-167. [CrossRef]

42. Zhang, H.; Xu, H.; Wu, M.; Zhong, Y.; Wang, D.; Jiao, Z. A soft-hard template approach towards hollow mesoporous silica nanoparticles with rough surfaces for controlled drug delivery and protein adsorption. J. Mater. Chem. B 2015, 3, 6480-6489. [CrossRef] 
43. Shin, T.; Fuji, M.; Takei, T.; Chikazawa, M.; Tanabe, K.; Mitsuhashi, K. Preparation of silica nano hollow particles using fine calcium particles as template. In Proceedings of the 105th Meeting of Soc. of Inorganic Materials, Kochi, Japan, 14-15 November 2002; pp. 78-79.

44. Fuji, M.; Takai, C.; Tarutani, Y.; Takei, Y.; Takahashi, M. Surface properties of nanosize hollow silica particles on the molecular level. Adv. Powder Technol. 2007, 18, 81-91. [CrossRef]

45. Fuji, M.; Shin, T.; Watanabe, H.; Takei, T. Shape-controlled hollow silica nanoparticles synthesized by an inorganic particle template method. Adv. Powder Technol. 2012, 23, 562-565. [CrossRef]

46. Le, Y.; Chen, J.-F.; Wang, J.-X.; Shao, L.; Wang, W.-C. A novel pathway for synthesis of silica hollow spheres with mesostructured walls. Mater. Lett. 2004, 58, 2105-2108. [CrossRef]

47. Nakashima, Y.; Takai, C.; Khosroshahi, H.R.; Suthabanditpong, W.; Fuji, M. Synthesis of ultra-small hollow silica nanoparticles using the prepared amorphous calcium carbonate in one-pot process. Adv. Powder Technol. 2018, 29, 904-908. [CrossRef]

48. Sharma, J.; Polizos, G.; Hun, D.; Nawaz, K.; Sahore, R. Low cost and scalable method for modifying surfaces of hollow particles from hydrophilic to hydrophobic. RSC Adv. 2020, 10, 31065-31069. [CrossRef]

49. Williamson, P.A.; Blower, P.J.; Green, M.A. Synthesis of porous hollow silica nanostructures using hydroxyapatite nanoparticle templates. Chem. Commun. 2011, 47, 1568-1570. [CrossRef]

50. SiliNax SPPN(b) from Nittestu Mining Co., Ltd., Tokyo, Japan. Available online: https:/ /www.nittetsukou.co.jp/rdd-e/products / prd_silinax.html (accessed on 20 June 2021).

51. Zhang, H.; Zhou, Y.; Li, Y.; Bandosz, T.J.; Akins, D.L. Synthesis of hollow ellipsoidal silica nanostructures using a wet-chemical etching approach. J. Colloid Interface Sci. 2012, 375, 106-111. [CrossRef]

52. Meng, Q.; Xiang, S.; Zhang, K.; Wang, M.; Bu, X.; Xue, P.; Liu, L.; Sun, H.; Yang, B. A facile two-step etching method to fabricate porous hollow silica particles. J. Colloid Interface Sci. 2012, 384, 22-28. [CrossRef]

53. Cho, Y.-S. Fabrication of hollow or macroporous silica particles by spray drying of colloidal dispersion. J. Dispers. Sci. Technol. 2016, 37, 23-33. [CrossRef]

54. Cheow, W.S.; Li, S.; Hadinoto, K. Spray drying formulation of hollow spherical aggregates of silica nanoparticles by experimental design. Chem. Eng. Res. Des. 2010, 88, 673-685. [CrossRef]

55. Zhao, J.-J.; Duan, Y.-Y.; Wang, X.-D.; Zhang, X.-R.; Han, Y.-H.; Gao, Y.-B.; Lv, Z.-H.; Yu, H.-T.; Wang, B.-X. Optical and radiative properties of infrared opacifier particles loaded in silica aerogels for high temperature thermal insulation. Int. J. Therm. Sci. 2013, 70, 54-64. [CrossRef]

56. Lee, D.; Stevens, P.C.; Zeng, S.Q.; Hunt, A.J. Thermal characterization of carbon-opacified silica aerogels. J. Non-Cryst. Solids 1995, 186, 285-290. [CrossRef]

57. Fricke, J.; Lu, X.; Wang, P.; Büttner, D.; Heinemann, U. Optimization of monolithic silica aerogel insulants. Int. J. Heat Mass Transf. 1992, 35, 2305-2309. [CrossRef]

58. Thapliyal, P.C.; Singh, K. Aerogels as promising thermal insulating materials: An overview. J. Mater. 2014. [CrossRef]

59. Rettelbach, T.; Sauberlich, J.; Korder, S.; Fricke, J. Thermal conductivity of silica aerogel powders at temperatures from 10 to $275 \mathrm{~K}$. J. Non-Cryst. Solids 1995, 186, 278-284. [CrossRef]

60. Datskos, P.; Sharma, J. Synthesis of Segmented Silica Rods by Regulation of the Growth Temperature. Angew. Chem. Int. Ed. 2014, 53, 331-598. [CrossRef]

61. Chawla, K.; Chauhan, A.P.S. Influence of carbon fillers on the thermal conductivity of Poly (methyl methacrylate)/carbon composites. AIP Conf. Proc. 2016, 1724, 020049.

62. Wang, J.; Li, Q.; Wu, C.; Xu, H. Thermal conductivity and mechanical properties of carbon black filled silicone rubber. Polym. Polym. Compos. 2014, 22, 393-400. [CrossRef]

63. Pollack, G.R. Kapitza resistance. Rev. Mod. Phys. 1969, 41, 48-81. [CrossRef] 